\title{
BANTUAN KOMPUTER DAN PELATIHAN PROGRAM MICROSOFT WORD BAGI GURU DAN MURID MADRASAH IBTIDAIYAH MUHAMMADIYAH DI SUKOHARJO DAN BOYOLALI
}

\author{
Muhammad Siam Priyono Nugroho ${ }^{1}$, Suryaning Setyowati ${ }^{2}$, Aliem Sudjatmiko ${ }^{3}$, \\ dan Umi Fadlilah ${ }^{4}$ \\ 1) Jurusan Teknik Arsitektur - Fakultas Teknik \\ 2) Jurusan Teknik Arsitektur - Fakultas Teknik \\ 3) Jurusan Teknik Sipil - Fakultas Teknik \\ 4) Jurusan Teknik Elektro - Fakultas Teknik \\ Universitas Muhammadiyah Surakarta \\ Jl. A. Yani Tromol Pos 1 Pabelan Kartasura 57102 Telp 0271717417 \\ Email: rekatjipta@mail2architect.com
}

\begin{abstract}
These community service activities program is a complete infrastructure of teaching and learning activities like computer device, gives additional knowledge and skills for teachers and students in computer field and use of simple application programs so they can complete task or job use computer facilities and be motivated to always follow the developments and advances in information technology, and encourage other parties to participate to provide assistance for other physical facilities. The problem faced by Islamic Elementary School Muhammadiyah and Islamic Elementary School Sraten Al Islam 2 Ngesrep Ngemplak Boyolali (Madrasah Ibtidaiyah Muhammadiyah Sraten and Madrasah Ibtidaiyah Al Islam 2 Ngesrep Ngemplak Boyolali ) is the absence of computers as a learning tool so that needs help and assistance are in the form of some form of computer training. Because of the availability of a number of computers that are not used in the Department of Architecture, Digital Architecture Laboratory FT-UMS and the availability of skilled human resource in the field of computers and training programs, so community service activities be held is in the form of computer assistance and training to Islamic Elementary School (Madrasah Ibtidaiyah ) teachers and students. Results of the Community Service activity is the availability of facilities or learning tool are in the form of computers and knowledge from training activities so its help teachers and students to know, study simple application program, and continue to develop skills independently through these facilities.
\end{abstract}

Kata Kunci : bantuan komputer, pelatihan, microsoft word, madrasah ibtidaiyah

\section{PENDAHULUAN}

\section{Analisis Situasi}

Pengembangan ketaqwaan, intelektual dan kepribadian seorang anak dimulai dan ditemtukan oleh lingkungannya, yang meliputi lingkungan keluarga, sekolah dan masyarakat. Keberhasilan anak dalam mengembangkan ketaqwaan intelektual dan 
kepribadiannya secara maksimal ditentukan dunia pendidikan dalam hal ini adalah Madrasah.

Madrasah Ibtidaiyah Muhammadiyah (MIM) Sraten merupakan lembaga pendidikan yang berlokasi di dukuh Piji desa Sraten Kecamatan Gatak Kabupaten Sukoharjo di jalanYogya-Solo km 15 yang mendidik dan mengembangkan intelektual serta kepribadian para siswa yang datang dari berbagai desa di Kecamatan Gatak. Kondisi MIM Sraten pada saat ini dirasa perlu penanganan dan pembenahan di segala bidang. Sebagai gambaran gedung MIM saat ini semua ruangan belum diplafon, lantainya sudah rusak atau tidak layak pakai, belum ada instalasi listrik, belum mempunyai KCK (masih bergabung dengan KCK Masjid), dan ruang perpustakaan yang kurang memadai. Selain itu keadaan sarana-sarana yang lain meja dan kursi murid sebagian besar rusak dan tidak layak pakai, meja kursi guru yang rusak, papan tulis rusak dan kekurangan buku-buku untuk perpustakaan.

Di samping itu Madrasah Ibtidah Al Islam 2 Ngesrep merupakan lembaga pendidikan lain yang beralamat di Tanjungsari Ngesrep Ngemplak Boyolali yang juga masih membutuhkan sarana dan prasarana. Keinginan menciptakan generasi yang terampil, menumbuhkan dan memupuk bakat yang dimiliki oleh siswa menjadi tujuan bagi lembaga pendidikan tersebut. Program kegiatan ekstrakurikuler pendidikan dan latihan komputer sampai saat ini belum terlaksana karena belum adanya sarana yang dibutuhkan.

Di lain pihak, Laboratorium Arsitektur Digital yang dimiliki oleh Jurusan Arsitektur Fakultas Teknik Universitas Muhammadiyah Surakarta memiliki sejumlah perangkat komputer yang sudah sangat tidak memadai untuk kegiatan praktikum (karena menggunakan prosesor Pentium I, RAM maksimum 32 MB, kapasitas harddisk maksimum 3 GB) dan sebagian dalam kondisi rusak. Namun perangkat komputer tersebut masih dapat diupayakan untuk difungsikan bagi kegiatan pengenalan komputer dengan program aplikasi yang standar. Kondisi tersebut yang melatarbelakangi dan mendorong Tim Pengabdian Masyarakat Fakultas Teknik UMS untuk melakukan pendampingan teknis melalui bantuan sarana prasarana berupa hibah komputer dan kegiatan pelatihan.

\section{Perumusan Masalah}

Meningkatnya perkembangan teknologi informasi khususnya bidang InformatikaKomputer harus diiringi dengan pengenalan dan pembelajaran komputer sejak usia dini. Penyediaan sarana prasarana pengenalan komputer menjadi hal penting yang tidak dapat dipisahkan.

Problem yang dihadapi Madrasah Ibtidaiyah Muhammadiyah Sraten dan Madrasah Ibtidaiyah Al Islam 2 Ngesrep Ngemplak Boyolali adalah ketiadaan perangkat komputer sebagai sarana pembelajaran. Hal ini jelas membutuhkan bantuan berupa sejumlah komputer dan pendampingan berupa pelatihan-pelatihan.

Berkenaan dengan ketersediaan sejumlah komputer yang sudah tidak dipergunakan di Laboratorium Arsitektur Digital Jurusan Arsitektur FT-UMS dan ketersediaan sumber daya manusia yang ahli di bidang komputer dan pelatihan program, maka kegiatan pengabdian masyarakat berupa bantuan komputer dan pelatihan kepada guru dan murid Madrasah Ibtidaiyah ini dirasa sangat tepat.

\section{Tujuan dan Manfaat Kegiatan}

Kegiatan pengabdian pada masyarakat yang dilakukan bertujuan untuk:

a. Melengkapi sarana prasarana kegiatan belajar mengajar berupa perangkat komputer. 
b. Memberikan tambahan ilmu dan keterampilan bagi guru dan murid di bidang komputer dan penggunaan program aplikasi sederhana sehingga guru dan murid dapat menyelesaikan tugas atau pekerjaan menggunakan sarana komputer dan termotivasi untuk selalu mengikuti perkembangan dan kemajuan teknologi informasi.

c. Mendorong pihak-pihak lain untuk turut berpartisipasi memberikan bantuan sarana fisik yang lain.

Manfaat yang dapat diperoleh dari kegiatan Pengabdian Masyarakat ini adalah tersedianya sarana atau alat pembelajaran berupa sejumlah perangkat komputer dan ilmu dari kegiatan pelatihan sehingga mempermudah guru dan murid untuk mengenal, belajar program aplikasi sederhana, dan terus mengembangkan ketrampilan secara mandiri melalui sarana tersebut.

\section{METODE PELAKSANAAN}

\section{Kerangka Pemecahan Masalah}

Kebutuhan sarana prasarana bagi kedua madrasah dapat dicarikan pemecahan melalui dua cara, yaitu pengajuan proposal bantuan dana atau cara dengan pengajuan proposal bantuan alat (fisik). Pengajuan dana membutuhkan nilai yang cukup besar mengingat harga untuk beberapa unit komputer relatif mahal. Cara kedua dengan pengajuan proposal bantuan alat lebih memungkinkan mengingat adanya perangkat di Laboratorium Arsitektur Digital yang sudah tidak terpakai dan akan dihibahkan. Untuk pendukung kegiatan ini dana diajukan melalui LP2M UMS.

Untuk kegiatan transfer ilmu kepada pihak madrasah yang mendapatkan bantuan komputer, ada beberapa alternatif sasaran yang dituju yaitu seluruh guru, seluruh murid, atau sebagian guru dan perwakilan murid. Pelatihan komputer kepada seluruh guru atau murid mempunyai kendala keterbatasan jumlah unit komputer yang dihibahkan. Pelatihan kepada seluruh murid tidak menjamin keberlanjutan karena ketika murid telah lulus, tidak terjadi transfer ilmu kepada adik kelasnya. Yang ideal adalah pelatihan kepada sebagian guru dan perwakilan murid, karena guru yang sudah mahir dapat melatih guru dan murid lain, sementara murid yang telah dilatih dapat menjadi asisten bagi guru yang bersangkutan.

\section{Khalayak Sasaran Antara Yang Strategis}

Bantuan komputer diserahkan kepada dua institusi pendidikan yaitu MIM Sraten Sukoharjo dan MI Al-Islam 2 Ngesrep Boyolali dimana sebagai institusi pendidikan akan menjadi wadah pembelajaran kepada murid secara terus menerus dan berkelanjutan. Pelatihan program aplikasi komputer dilakukan pada guru yang ditunjuk oleh pihak sekolah dan perwakilan murid sesuai dengan jumlah unit komputer yang tersedia. Diharapkan nantinya setelah program pelatihan dilaksanakan, guru yang telah dilatih dapat menularkan ilmunya kepada guru yang lain dan pada murid-muridnya, dan perwakilan murid yang sudah mahir dapat menjadi asisten guru dalam mengajarkan kepada murid yang lain.

\section{Keterkaitan}

Kegiatan ini melibatkan Tim Pengabdian FT-UMS dan dua institusi sasaran yaitu Madrasah Ibtidaiyah Muhammadiyah (MIM) Sraten yang berlokasi di dukuh Piji desa Sraten Kecamatan Gatak Kabupaten Sukoharjo dan Madrasah Ibtidah Al-Islam 2 Ngesrep di Tanjungsari Ngesrep Ngemplak Boyolali. Tim Pengabdian FT-UMS berperan sebagai institusi yang memberikan bantuan sarana prasarana dan pelatihan, sementara dua institusi Madrasah Ibtidaiyah yang menerima dan mendapatkan manfaat fisik 
dan keilmuan. Tim Pengabdian FT-UMS juga mendapatkan wadah bagi kegiatan pengabdian kepada masyarakat sebagai bagian dari kewajiban Tri Dharma Perguruan Tinggi dan secara tidak langsung mengenalkan perguruan tinggi kepada masyarakat.

\section{Metode Kegiatan}

Metode Kegiatan Pengabdian pada Masyarakat ini direncanakan dengan tahapan-tahapan berikut :

a. Permohonan dari pihak pengelola MIM Sraten Sukoharjo dan MI Al-Islam 2 Ngesrep Boyolali. Pada tahap ini pihak pengelola MIM Sraten dan MI Al-Islam 2 Ngesrep mengajukan proposal permohonan sejumlah perangkat komputer untuk mendukung sarana sekolah.

b. Permohonan ini ditanggapi secara positif dan aktif oleh Tim Pengabdian Masyarakat FT - UMS dengan mengajukan proposal kepada pihak LP2M UMS.

c. Pendataan, pengecekan dan perbaikan komputer yang ada di Laboratorium Arsitektur Digital Jurusan Arsitektur FTUMS untuk mengetahui kondisi dan kelayakan komputer. Hal ini dilakukan oleh siswa-siswa PKL yang magang di Laboratorium Komputer Fakultas Teknik UMS.

d. Survei lokasi dan kunjungan ke MIM Sraten Sukoharjo dan MI Al Islam 2 Ngesrep Boyolali. Tahapan ini dilakukan untuk mengetahui kondisi secara nyata dan mendata secara fisik prasarana yang ada agar bantuan sarana komputer dan pelatihan dapat tepat sasaran.

e. Pengiriman komputer ke lokasi dan bantuan teknis pemasangan/instalasi apabila diperlukan.

f. Kegiatan pengenalan dan pelatihan aplikasi komputer bagi para guru dan perwakilan murid MIM Sraten Sukoharjo dan MI Al-Islam 2 Ngesrep Boyolali. Pada tahap ini Tim Pengabdian mengadakan pelatihan aplikasi komputer sederhana yaitu Microsoft Word sehingga nantinya para guru dan perwakilan murid dapat mengembangkan secara mandiri untuk melatih guru dan murid lain untuk belajar komputer.

g. Evaluasi. Pada tahap ini Tim Pengabdian Masyarakat FT-UMS akan memaparkan hasil kegiatan yang telah dilaksanakan dan memberikan kesempatan kepada pihak sekolah MIM Sraten dan MI Al Islam 2 Ngesrep Ngemplak Boyolali untuk menyampaikan tanggapan dan koreksi.

\section{HASIL DAN PEMBAHASAN \\ 1. Realisasi Kegiatan}

Sesuai dengan rencana kegiatan pengabdian masyarakat yang diusulkan pelaksanaan, hasil tiap tahapan kegiatan diuraikan sebagai berikut:

a. Permohonan dari pihak pengelola MIM Sraten Sukoharjo dan MI Al-Islam 2 Ngesrep Boyolali

b. Pada tahap ini pihak pengelola MIM Sraten dan MI Al-Islam 2 Ngesrep mengajukan proposal permohonan sejumlah perangkat komputer untuk mendukung sarana sekolah.

c. Tanggapan Tim Pengabdian Masyarakat Fakultas Teknik UMS

d. Permohonan ini ditanggapi secara positif dan aktif oleh Tim Pengabdian Masyarakat FT-UMS dengan mengajukan proposal kepada pihak LP2M UMS tanggal 8 Maret 2010 dan disetujui dengan SK. Ketua LP2M No : 14/A.3-III/LPPM/IV/ 2010 tanggal 6 April 2010.

e. Kegiatan Pendataan, Pengecekan, dan Perbaikan Komputer

f. Pendataan, pengecekan dan perbaikan komputer dilakukan di Laboratorium Arsitektur Digital Jurusan Arsitektur FTUMS untuk mengetahui kondisi dan kelayakan komputer. Hal ini dilakukan 
oleh siswa-siswa PKL yang magang di Laboratorium Komputer Fakultas Teknik UMS. Proses kegiatan sebagai berikut:

1) Mengecek kondisi komputer berjumlah 20 unit dilihat dari tingkat kerusakan.

2) Memisahkan komputer yang rusak (masih dapat diperbaiki) berjumlah 11 unit dan 9 unit kondisi tidak dapat diperbaiki.

3) Proses perbaikan tiap unit komputer, melepas komponen perangkat keras kemudian menginstall ulang. Pada proses ini diperlukan CD ROM sistem operasi Windows 95 dan MS Office 98.

4) Proses Packing, merakit kembali perangkat komputer dengan menandai tiap unit komputer agar mudah dideteksi apabila terjadi kesalahan memasang atau terjadi kerusakan ulang.

h. Penyerahan Bantuan Komputer ke Madrasah

Dilakukan kunjungan ke MIM Sraten Sukoharjo dan MI Al Islam 2 Ngesrep Boyolali. Tahapan ini dilakukan untuk mengetahui kondisi secara nyata dan mendata secara fisik prasarana yang ada agar bantuan sarana komputer dan pelatihan dapat tepat sasaran. Selanjutnya dilakukan pengiriman komputer ke lokasi dan bantuan teknis pemasangan/instalasi apabila diperlukan. Setelah komputer dipasang selanjutnya tim pengabdian masyarakat mengunjungi Madrasah untuk mengecek kondisi komputer yang telah dipasang dan memberikan meja komputer untuk melengkapi fasilitas yang ada. Kegiatan ini dilaksanakan pada hari Selasa tanggal 4 Mei 2010. Kondisi di lapangan, Madrasah Ibtidaiyah Al Islam 2 Ngesrep Boyolali belum mempunyai meja komputer atau masih meminjam dari SD lain, sehingga hal ini sangat membantu fasilitas Madrasah.

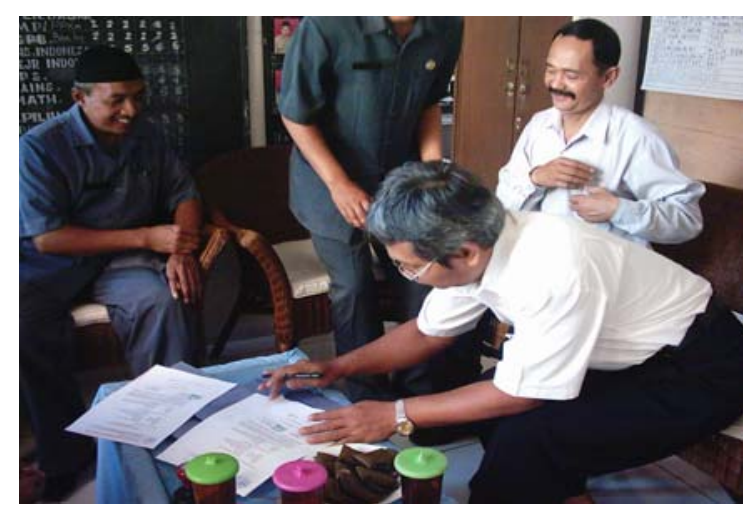

Gambar 3

Perangkat komputer dari Tim Pengabdian Masyarakat FT-UMS yang ditempatkan di Laboratorium Komputer MIM Sraten Sukoharjo Sumber : dokumentasi TIM, 2010

Gambar 4

Pengangkutan dan penyerahan meja komputer baru oleh Tim Pengabdian Masyarakat FT-UMS kepada MIM Sraten Sukoharjo

Sumber: dokumentasi TIM, 2010 
Gambar 5

Serah terima perangkat komputer dan meja oleh Tim Pengabdian Masyarakat FT-UMS kepada Al Islam 2 Ngesrep Boyolali Sumber: dokumentasi TIM, 2010

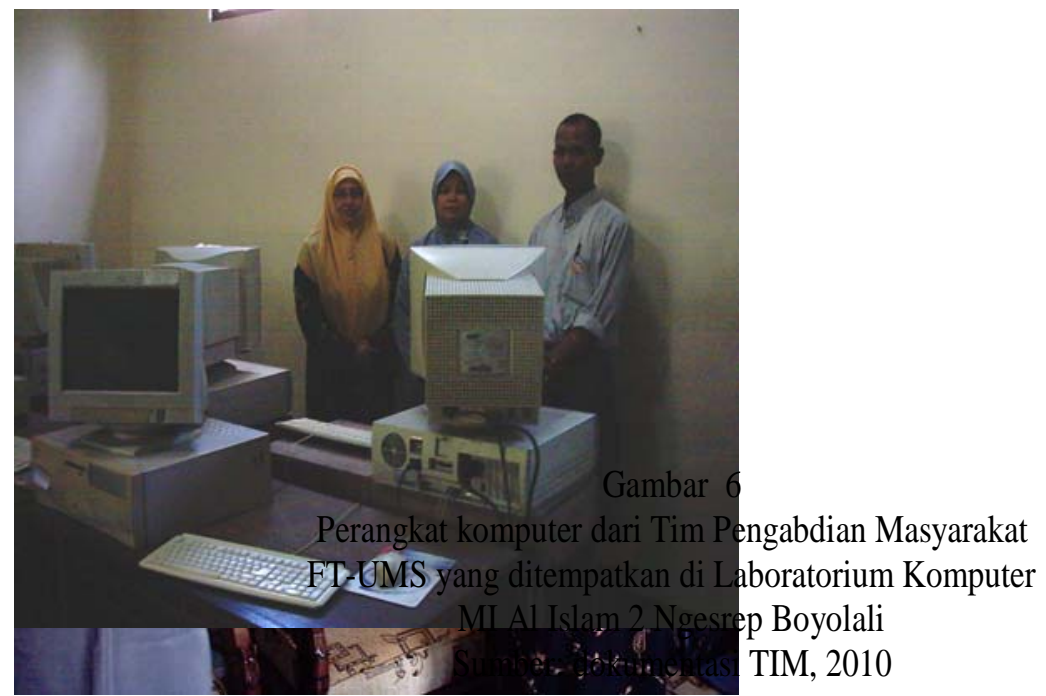

1. Kegiatan pengenalan dan pelatihan aplikasi komputer bagi para guru dan perwakilan murid MIM Sraten Sukoharjo dan MI Al-Islam 2 Ngesrep Boyolali. Pada tahap ini Tim Pengabdian mengadakan pelatihan aplikasi komputer sederhana yaitu Microsoft Word sehingga nantinya para guru dan perwakilan murid dapat mengembangkan secara mandiri untuk melatih guru dan murid lain untuk belajar komputer. Kegiatan ini dilakukan pada Sabtu 7 Agustus 2010. Sebagai pelengkap tim pengabdian masyarakat membuat modul pelatihan komputer dengan tujuan pelatihan lebih mudah dan jelas diterapkan.

j. Evaluasi

Pada tahap ini Tim Pengabdian Masyarakat FT-UMS mengevaluasi program kegiatan yang dilaksanakan sebelum dan sesudah adanya bantuan komputer baik di sekolah MIM Sraten dan MI Al Islam 2 Ngesrep Ngemplak Boyolali. Selain itu Tim Pengabdian Masyarakat juga member kesempatan bagi pihak Madrasah untuk memberikan masukan bagi Tim tentang pelaksanaan program.

Hasil Evaluasi Kegiatan Aplikasi Komputer:

1) Madrasah Ibtidaiyah Al Islam 2 Ngesrep Boyolali

Pelaksanaan program pengabdian masyarakat di MI Al Islam 2 Ngesrep Boyolali memberikan dampak positif bagi pelaksanaan kegiatan ekstra kulikuler siswa madrasah sebagai berikut:

a) Bertambahnya fasilitas komputer memberikan kemudahan kegiatan ekstrakulikuler yaitu sebelum mendapat bantuan MI Al Islam sudah memiliki 6 komputer dan 1 komputer dipakai 3-4 siswa. Setelah mendapat bantuan 6 komputer, siswa dapat memakai komputer lebih longgar yaitu 1 komputer dipakai 1-2 siswa.

b) Setelah adanya pelatihan dari tim pengabdian masyarakat, siswa mendapatkan materi lebih variatif yaitu belajar power point. Materi sebelumnya; (1) perkenalan kom- 
puter, (2) menggambar (paint), (3) typing (word art) dan menyisipkan gambar.

c) Waktu pelaksanaan lebih singkat, sebelum mendapat bantuan pelaksanaan ekstra kulikuler selama 1 minggu dan setelah mendapat bantuan komputer pelaksanaan ekstrakulikuler pelaksanaan hanya 4 hari yaitu Senin - Kamis pukul 12.30 - 13.30 (Sumber: Sri Ahmayuti, S.Pd dan Triningsih Karimah, guru komputer).

2) Madrasah Ibtidaiyah Muhammadiyah Sraten Sukoharjo.

Pelaksanaan program pengabdian masyarakat di MI Muhammadiyah Sraten Sukoharjo memberikan dampak positif bagi gairah belajar komputer dan akhirnya memberikan dampak bagi orang tua murid berinisiatif untuk membelikan komputer di rumah. Hal ini sangat membantu pelaksanaan kegiatan ekstrakulikuler siswa dalam pembuatan tugas-tugas latihan (Sumber: Agus Widada dan Taruna Mursita, guru komputer).

Hasil kegiatan dari program pengabdian masyarakat ini adalah terbantunya sarana komputer bagi dua Madrasah Ibtidaiyah di Sukoharjo dan Boyolali sehingga siswa-siswa Madrasah tersebut dapat belajar aplikasi komputer dan pelatihan yang dilengkapi modul sehingga lebih mudah dalam melakukan praktek aplikasi komputer.

Sebagai evaluasi pada rencana kegiatan, keluaran program kegiatan ini adalah adanya dampak positif bagi Madrasah maupun siswa-siswanya yaitu dengan terbantunya sarana komputer maka dapat mempercepat proses pembelajaran dan meningkatnya antusiame belajar para siswa madrasah.
Adapun faktor pendorong keberhasilan program adalah adanya komunikasi serta kerjasama yang baik dari awal proses survei, penyerahan bantuan, pelatihan, dan evaluasi Sedangkan hambatan yang dirasakan oleh tim pelaksana maupun madrasah yaitu dengan perkembangan software dan wacana open source maka perlu disiapkan perangkat lunak maupun sumber daya manusia yang ada.

\section{SIMPULAN DAN SARAN}

\section{Simpulan}

Berdasarkan laporan pelaksanaan kegiatan program pengabdian masyarakat tersebut diatas dapat disimpulkan bahwa kegiatan pengabdian masyarakat dengan hasil terbantunya sarana komputer bagi dua Madrasah Ibtidaiyah di Sukoharjo dan Boyolali sehingga siswa-siswa Madrasah tersebut dapat belajar aplikasi komputer dan pelatihan yang dilengkapi modul sehingga lebih mudah dalam melakukan praktek aplikasi komputer. Pengabdian Masyarakat ini merupakan hasil kerjasama yang baik antara Tim UMS dengan pihak Madrasah Ibtidaiyah Muhammadiyah di lingkungan Surakarta yang mengajukan usulan permohonan bantuan komputer sehingga program ini merupakan proyek nyata yang sangat dibutuhkan oleh pihak mitra dalam hal ini Madrasah Ibtidaiyah Muhammadiyah Sraten dan Madrasah Ibtidaiyah Al Islam 2 Ngesrep Ngemplak Boyolali.

\section{Saran}

Saran untuk kegiatan selanjutnya adalah memberikan bantuan kepada Madrasah Ibtidaiyah yang lain agar lebih merata di lingkungan pendidikan Islam khususnya Muhammadiyah dan memperkenalkan wacana program open source kepada pihak sekolah. 


\section{DAFTAR PUSTAKA}

Anggawirya, Erhans, 2003, Microsof Office XP, Jakarta : PT. Ercontara Rajawali

Priyono Nugroho, M.S., 2007, Panduan Praktikum Dasar Pemrograman Komputer bagi Mahasiswa Arsitektur, Laboratorium Arsitektur Digital FT-UMS

Sutanta, Edhy, 2005, Pengantar Teknologi Informasi, Jogjakarta : Penerbit Graha Ilmu 
Bantuan Komputer dan Pelatihan Komputer Program Wicrosoft Word bagi Guru dan Murid Madrasah Ibtidaiyah Muhammadiyah di Sukoharjo dan Boyolali oleh: MS

Priyono., dkk. 